\title{
M918V RET mutation causes familial medullary thyroid carcinoma: study of 8 affected kindreds
}

\author{
M Cecília Martins-Costa1,2,3, Lucas L Cunha', Susan C Lindsey', Cleber P Camacho', \\ Renata P Dotto', Gilberto K Furuzawa', M Sharmila A Sousa', Teresa S Kasamatsu', \\ Ilda S Kunii', Márcio M Martins', Alberto L Machado1,4, João R M Martins', \\ Magnus R Dias-da-Silva' and Rui M B Maciel11,4
}

'Department of Medicine, Thyroid Diseases Center and Laboratory of Molecular and Translational Endocrinology, Division of Endocrinology, Escola Paulista de Medicina, Universidade Federal de São Paulo, São Paulo, SP, Brazil ${ }^{2}$ Center for Endocrinology and Metabology, Hospital Geral de Fortaleza, Fortaleza, CE, Brazil ${ }^{3}$ Department of Medicine, Universidade de Fortaleza, Fortaleza, CE, Brazil ${ }^{4}$ Fleury Medicine and Health, São Paulo, SP, Brazil

\begin{abstract}
Germline mutations in codon 918 of exon 16 of the RET gene (M918T) are classically associated with multiple endocrine neoplasia type 2B (MEN 2B) with highly aggressive medullary thyroid cancer (MTC), pheochromocytoma and a unique phenotype. The objectives of this study are to describe the rare M918V RET mutation discovered in 8 MTC kindreds from Brazil lacking the MEN 2B phenotype classically observed in M918T patients and to investigate the presence of a founder effect for this germline mutation. Eight apparently sporadic MTC cases were diagnosed with the germline M918V RET mutation. Subsequently, their relatives underwent clinical and genetic assessment $(n=113)$, and M918V was found in 42 of them. Until today, 20/50 M918V carriers underwent thyroidectomy and all presented MTC/C-cell hyperplasia; the remainder carriers are on clinical follow-up. None of the M918V carriers presented clinical features of MEN 2B. Their clinical presentation was heterogeneous, and the age at tumor diagnosis ranged from 24 to 59 years. Lymph node metastases were present in 12/20 patients, and presumable distant metastases in 2/20; in contrast, we observed a carrier of up to 87 years of age without evidence of MTC. Ethnographic fieldwork and haplotype analyses suggested that the founder mutation first settled in that area fifteen generations ago and originated from Portugal. Our study is the first to demonstrate the RET M918V mutation co-segregating in 8 familial MTC kindreds with validated evidence of a founder effect. We suggest that M918V MTC should be clinically considered an American Thyroid Association (ATA) moderate-risk category.
\end{abstract}

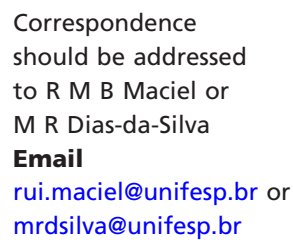


The understanding of the genotype/phenotype correlation of RET mutations has increased over recent decades due to the widespread practice of RET sequencing and careful long-term clinical follow-up of affected kindreds (Signorini et al. 2014, Wells et al. 2015). This knowledge has allowed recommendations on the timing of prophylactic thyroidectomy and surgery extent based on stratified mutation risk levels (Brandi et al. 2001, Kloos et al. 2009, Wells et al. 2015). In fact, increased genetic screening for RET mutations, particularly for apparently sporadic MTC, has also led to the possibility of discovering new mutations of which the transforming activity remains uncertain (Chen et al. 2010).

Germline mutations in codon 918 in exon 16 of the RET gene (M918T) are characteristically associated with multiple endocrine neoplasia type 2B (MEN 2B) with highly aggressive MTC, PHEO and a unique phenotype (Carlson et al. 1994, Hofstra et al. 1994, Eng et al. 1994, Wells et al. 2013, 2015, Frank-Raue \& Raue 2015). To date, the M918V variation was described in only one patient with MTC in a large Italian cohort and in one family member who had not developed MTC at the time of publication (Cosci et al. 2011).

Here, we describe this rare methionine-to-valine substitution in the 918 codon of the RET gene in eight MTC kindreds without the MEN2B phenotype classically observed in M918T patients. Moreover, we report the clinical, molecular and histological features of such families and the presence of a founder effect for this germline mutation.

\section{Patients and methods}

\section{Index patients, their relatives and controls}

As part of the Brazilian Research Consortium for Multiple Endocrine Neoplasia (BRASMEN), we evaluated 60 index cases of MTC (31 sporadic, 28 MEN 2A and 1 MEN 2B) in Ceará, a Northeastern State of Brazil. Eight apparently sporadic MTC patients were identified with the M918V RET mutation. Then, we have invited the relatives at-risk to enter in this study and, at the time of this report, 113 (female $n=84$; male $n=29$ ) members were assessed.

Additionally, 40 thyroid-healthy individuals originating from the same state but unrelated to the patients were investigated as a control group.

The study protocol was approved by the internal review board of the Universidade Federal de São Paulo (CAAE: 16441414.9.1001.5505111), and all patients received genetic counseling before and after RET testing.

\section{Clinical evaluation and follow-up of M918V carriers}

Clinical evaluation consisted of medical history and physical examination. We particularly looked for syndromic features and the MEN 2B phenotype, including PHEO, marfanoid habitus, mucosal neuromas and ganglioneuromatosis (Camacho et al. 2008).

We performed peripheral blood collection to assess calcitonin, carcinoembryonic antigen (CEA), thyroid-stimulating hormone (TSH), free thyroxine (FT4), parathyroid hormone (PTH) and total calcium measurements. For those who presented PTH levels above the upper limit of the range, we measured 25-hydroxyvitamin $\mathrm{D}$. We also measured plasma metanephrines, as well as 24-h urinary catecholamines and metanephrines for biochemical investigation of PHEO.

Cervical and abdominal ultrasound (US) was performed with a LOGIQ scanner (GE Healthcare BioScience) using a 12-MHz transducer integrated with colorDoppler examination. Thyroid nodules with suspicious features for malignancy were submitted to US-guided fine needle aspiration biopsy (FNAB) using a 23-gauge needle $(25 \times 0.6 \mathrm{~mm})$ attached to a $10-\mathrm{mL}$ syringe.

For patients with an MTC diagnosis, the clinical management, including imaging investigation, was performed in accordance with American Thyroid Association (ATA) guidelines (Kloos et al. 2009, Wells et al. 2015). However, because the M918V mutation has not yet been classified in any MTC guideline, we clinically approached the carriers based on serum calcitonin and CEA measurements, as well as the FNAB results of detected thyroid nodules; only those patients with positive results for these tests were referred for surgery. After histological confirmation of MTC, and classification of the neoplasia according to the TNM (tumor, node, metastasis) staging system (American Journal Committee on Cancer 2010), those patients were followed in accordance with the ATA guidelines (Wells et al. 2015). The remaining carriers who present normal calcitonin and cervical ultrasound examination were maintained on a careful follow-up.

\section{Laboratory studies}

Basal plasma calcitonin was measured using an in-house immunofluorometric assay, with cut-off values of $18.4 \mathrm{pg} / \mathrm{mL}$ for males and $7.8 \mathrm{pg} / \mathrm{mL}$ for females (Camacho et al. 2014). CEA, TSH and FT4 were measured by electrochemiluminescent immunoassays (Elecsys analyzer, Roche Diagnostics $\mathrm{GmbH}$ ). The normal ranges

Published by Bioscientifica Ltd 
were as follows: CEA, smokers: $<5 \mathrm{ng} / \mathrm{mL}$, non-smokers: $<3 \mathrm{ng} / \mathrm{mL}$; TSH, 0.27-4.2 mIU/L; FT4, 0.93-1.7 ng/dL; and PTH, $15-65 \mathrm{ng} / \mathrm{mL}$. Total calcium was measured using a colorimetric assay (Olympus AU400 analyzer, Beckman Coulter Biomedical K.K., Shizuoka, Japan). The normal ranges were $8.8-10.6 \mathrm{mg} / \mathrm{dL}$ for adults and $8.5-11 \mathrm{mg} / \mathrm{dL}$ for children. The 25-hydroxyvitamin $\mathrm{D}$ levels were measured using a immunochemiluminescent assay. The normal range was 30-60 ng/mL (Maeda et al. 2014). Plasma metanephrines were measured using liquid chromatography-tandem mass spectrometry (XEVO TQ-S, Milford, MA, USA), and the normal range was $<0.5 \mathrm{nmol} / \mathrm{L}$ for metanephrine and $<0.9 \mathrm{nmol} / \mathrm{L}$ for normetanephrine. Urinary catecholamines and metanephrines were measured using high-performance liquid chromatography (Chromsystems Instruments \& Chemicals GmgH, Munich, Germany). The normal ranges for catecholamines were as follows: up to $97 \mu \mathrm{g} / 24 \mathrm{~h}$ for norepinephrine, up to $500 \mu \mathrm{g} / 24 \mathrm{~h}$ for dopamine and up to $27 \mu \mathrm{g} / 24 \mathrm{~h}$ for epinephrine. The normal ranges for metanephrines were as follows: up to $320 \mu \mathrm{g} / 24 \mathrm{~h}$ for metanephrine and up to $390 \mu \mathrm{g} / 24 \mathrm{~h}$ normetanephrine.

Genomic DNA was extracted from peripheral blood leukocytes using an in-house protocol (Kizys et al. 2012). Sequence analysis of hot-spot bearing exons $8,10,11$ and 13-16 was performed; in addition, extended RET gene analysis was performed in all M918V carriers who had histopathological confirmation of $\mathrm{MTC} / \mathrm{CCH}$ to exclude mutations in other exons (Lindsey et al. 2012). Briefly, each exon was sequenced at least twice and in both directions. The cycling conditions were as follows: $5 \mathrm{~min}$ at $94^{\circ} \mathrm{C}$, followed by 38 cycles of $20 \mathrm{~s}$ each at $94^{\circ} \mathrm{C}$ and $30 \mathrm{~s}$ at $60^{\circ} \mathrm{C}$ and an extension step of $2 \mathrm{~min}$ at $72^{\circ} \mathrm{C}$. PCR products were direct-sequenced using an ABI Prism Big Dye Terminator Cycle Sequencing Ready Reaction Kit (Applied Biosystems). The sequences were analyzed using the BioEdit Sequence Alignment Editor and CLC Main Workbench 6 (http://www.clcbio.com) and compared with reference data available in the NCBI GenBank (RefSeq NG_007489) and the Ensembl Genome Browser (Lindsey et al. 2012).

\section{Genealogical fieldwork}

The observation that the highest concentration of patients with the M918V RET mutation occurred in the same region in the northeast area of the State of Ceará in association with the anecdotal perception of high consanguinity among inhabitants led us to perform a genealogical investigation of the families, including data collection from these families in the local church and municipality archives, such as birth, marriage and death registries.

\section{Founder effect and mutation age estimation analysis}

We hypothesized that a founder effect would explain the high frequency of the M918V RET mutation in those patients from northeastern Ceará. Haplotype analysis of four RET-flanking microsatellite markers, D10S197, D10S196, D10S1652 and D10S537, was performed to track the founder effect (Qi et al. 2011). The first marker was placed at position $50.04 \mathrm{cM}$, and the other three markers were at positions $70.07,80.61$ and $89.16 \mathrm{cM}$. The chromosome map distances were derived from the deCODE map (https://www.ncbi.nlm.nih.gov/probe/).

GenePop was used to perform the Hardy-Weinberg exact test (Rousset 2008). Haplotypes of the patients and controls were reconstructed using the statistical software package PHASE, version 2.1 (Stephens et al. 2001, Stephens \& Donnelly 2003, Stephens \& Scheet 2005). We constructed the phylogenetic tree of the studied families with POPTREE2 software by estimating the genetic distance measures (Takezaki et al. 2010).

The proportion of haplotypes commonly observed in all carriers was reduced with time. This allowed us to estimate the age of the founder mutation. Disease mapping using Linkage disEquilibrium (DMLE) version 2.3 (Reeve \& Rannala 2002) estimated the age of M918V RET mutation based on the disease chromosomes sampled and the population growth rate. Because the M918V RET mutation was recently described (Cosci et al. 2011), the proportion of chromosomes sampled was difficult to calculate. Therefore, three different analyses were performed using a different calculation for the proportion of mutation-carrying chromosomes sampled: 0.015, 0.01 and 0.005 (Caleca et al. 2014). The population growth rate was estimated as described previously (Papi et al. 2009).

\section{Statistical analysis}

The primary data are presented as the mean \pm standard deviation (s.D.), median and minimal and maximal values. SPSS software (version 23; SPSS) was used to perform the analysis. A $P$ value $<0.05$ was considered significant. 


\section{Results}

\section{Clinical and genetic diagnosis of FMTC in eight kindreds carrying the RET M918V mutation}

After the detection of the germline M918V RET mutation in 8 apparently unrelated MTC indexes cases, we extended the analysis to their relatives (Fig. 1). Consequently, we have studied 121 individuals ( 83 women and 38 men), being 8 index cases and 113 at-risk relatives. From these 113 at-risk relatives screened, 42 were diagnosed with this mutation and 71 were non-carriers. In 2 families (F3 and F6), the mutation was identified in 2 generations. In 3 families (F1, F4 and F5), the mutation was identified in
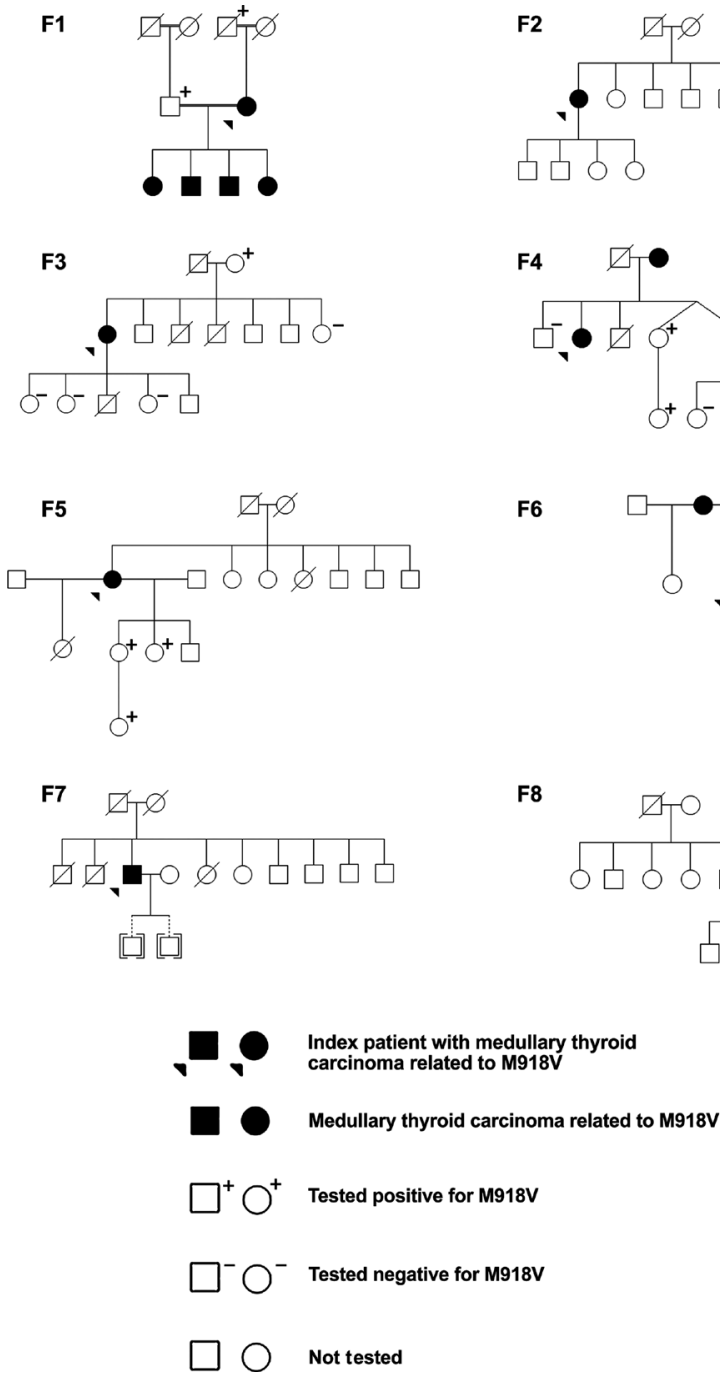

\section{Figure 1}

Pedigree of eight apparently unrelated MTC families identified through the study. Indexes cases are identified by black arrows. Full black icons represent either affected MTC proband or relatives. The sons of F7.3 are adopted.
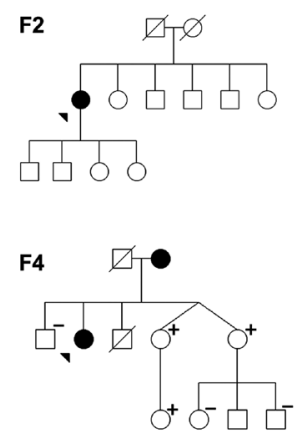

F6

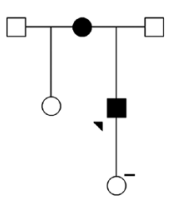

F8

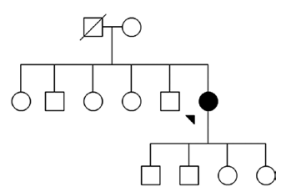

3 generations. For 3 index cases (F2, F7 and F8), only one individual is noticeably affected because the other family members have not answered our call for the clinical and genetic evaluation to date (Fig. 1).

At the moment of RET screening, 4 of these 42 M918V-positive relatives had already been submitted to total thyroidectomy, although they were not aware that their thyroid disease had a hereditary component and that it was related to a common bond with index patients (patients F1.6, F1.7, F1.8 and F1.9). The remainder 38 relatives positive for $\mathrm{M} 918 \mathrm{~V}$ had not performed any surgical procedure at the time of RET screening.

The clinical and biochemical features of all M918V carriers are shown in Table 1. At the initial assessment after RET screening, $42 \%$ (14/33) of the patients presented serum calcitonin levels above the limit of reference; $20 \%$ (6/30) had elevated CEA. Two of 25 patients presented elevations of PTH, both related to decreased levels of vitamin D (18 and $21 \mathrm{ng} / \mathrm{mL}$ ). None of the M918V carriers presented hypercalcemia or elevation of plasma and $24-\mathrm{h}$ urinary metanephrines.

Therefore, from the $50 \mathrm{M} 918 \mathrm{~V}$ carriers, 8 were index cases, 4 were relatives who had already performed total thyroidectomy at the time of RET screening and 38 were relatives who came to RET screening without a history of previous thyroidectomy. From the 38 relatives of this latter group, we have proposed surgical treatment in 8 (F1.1, F1.2, F1.3, F1.4, F1.5, F1.10, F4.1 and F6.1) because we have noticed elevated serum calcitonin and suspicious thyroid nodules or cervical lymph nodes by cervical ultrasound, some of them associated to suspicious or positive results on cytology after FNAB (Table 2). After surgery, we have observed MTC or C-cell hyperplasia $(\mathrm{CCH})$ in all $20 \mathrm{M} 918 \mathrm{~V}$ operated carriers (Table 2).

The clinical presentation of MTC in the index cases varied considerably, particularly for the age at diagnosis and the TNM (tumor, node and metastasis) staging (Table 2). For the index cases, the youngest patient was diagnosed with MTC at 24 years of age (F6); however, at age 16 , he noticed a nodule on the left side of his neck; the lesion was investigated 8 years later because the nodule persistently increased in volume. He presented the most advanced postoperative TNM stage of this cohort. The oldest M918V index case was diagnosed at 59 years of age (T2mN1bM0), and the follow-up did not reveal evidence of biochemical or structural disease (F5). Additionally, one of the M918V index cases (F8) was diagnosed at age 41 years with a $1-\mathrm{cm}$ MTC confined to the thyroid gland. To date, she has no sign of metastatic lymph nodes, unlike the other index cases (7/8), which had lymph node

Published by Bioscientifica Ltd 
2

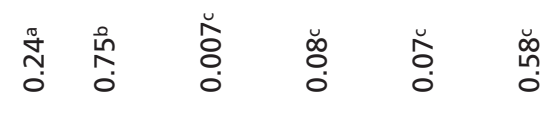

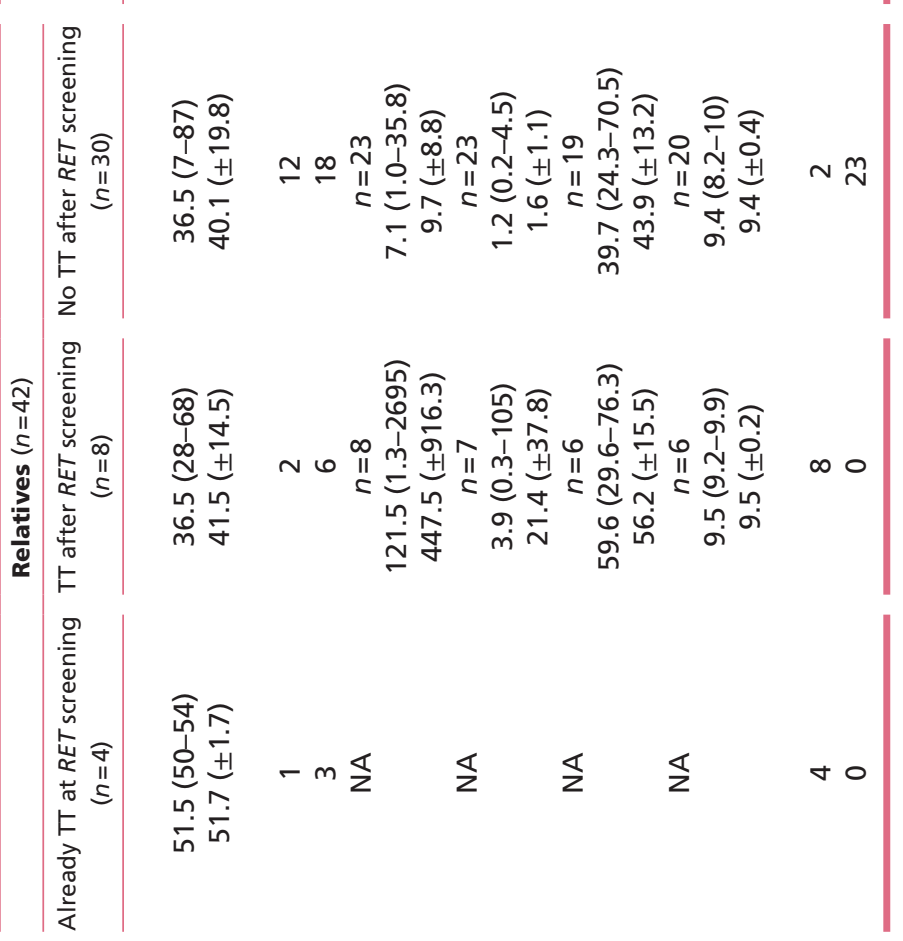

$\frac{\sqrt{2}}{\frac{\pi}{20}}$

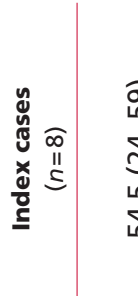

空

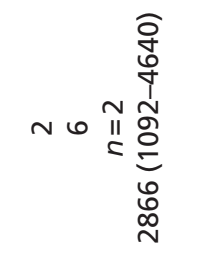

$\mathbb{2} \mathbb{\pi}$

$\infty 0$

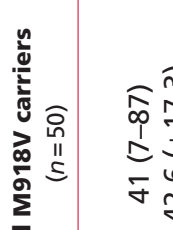

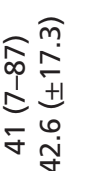

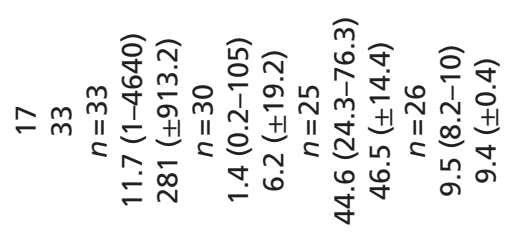

N

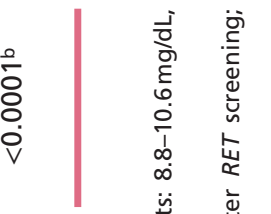

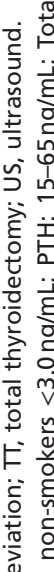

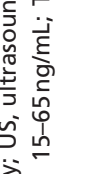

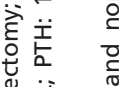

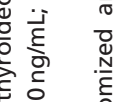

蒂

峁

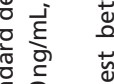

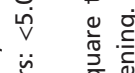

iे

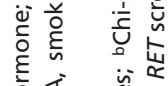

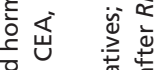

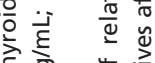

क्ष

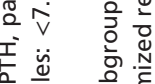

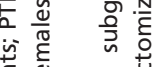

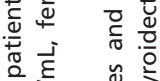

पे है

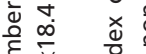

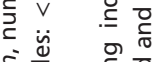

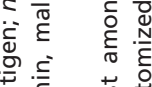

4.

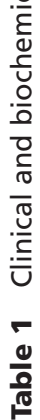

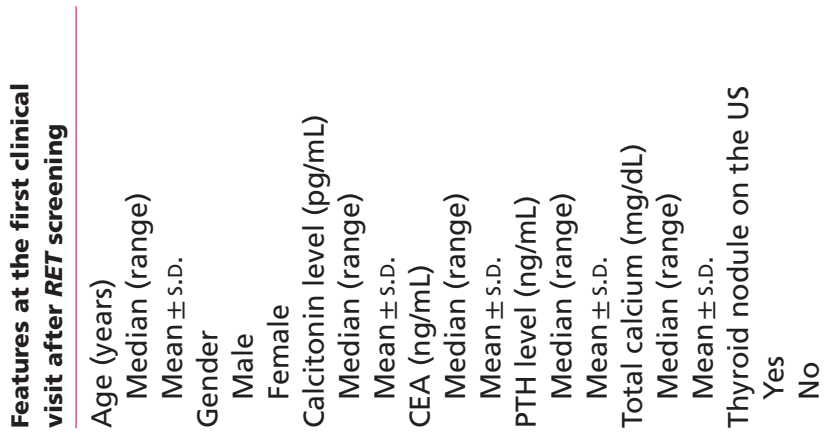

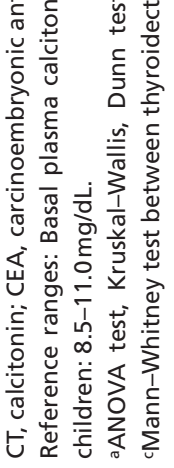




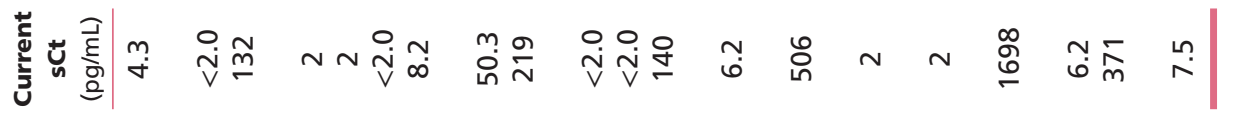

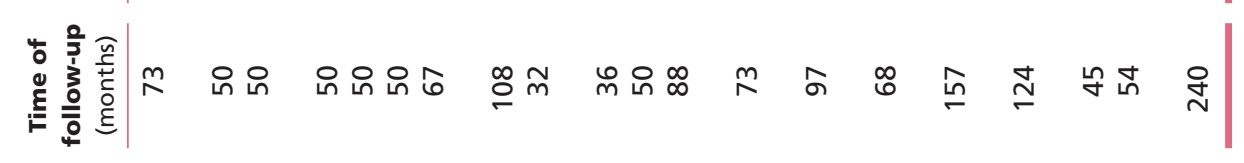

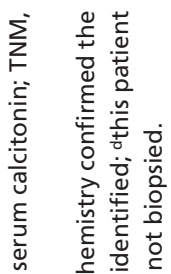

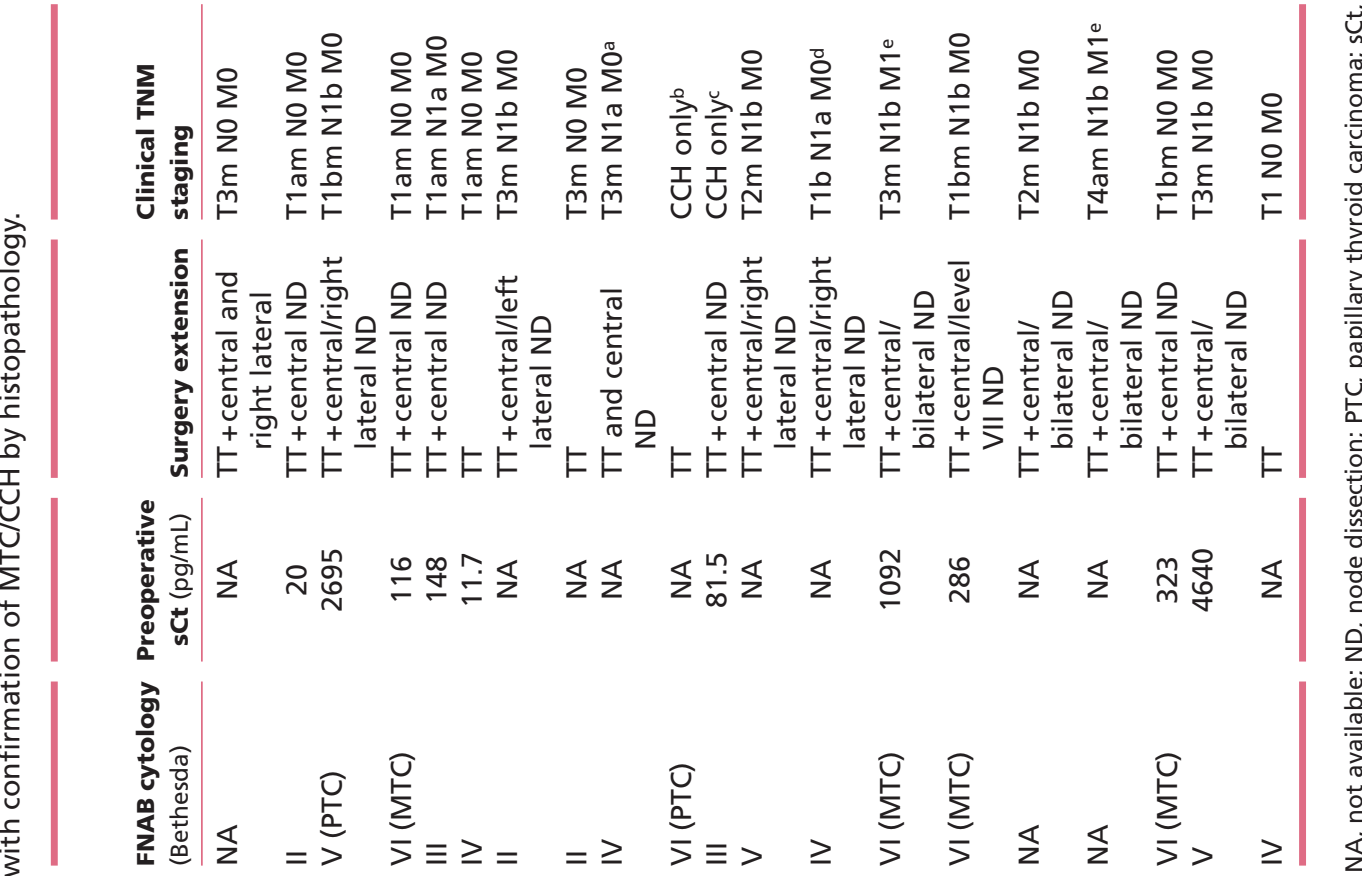

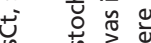
总

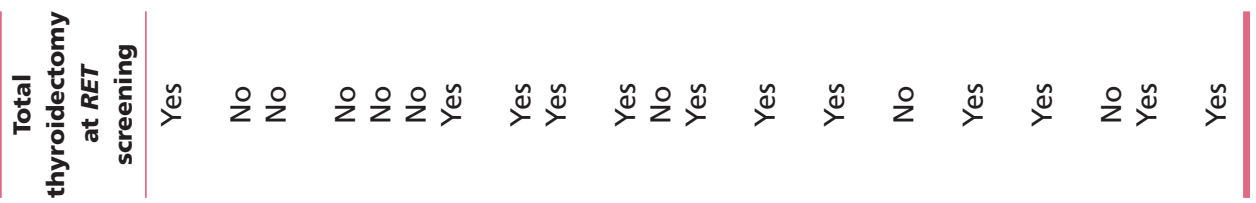

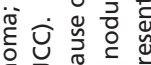

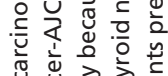
응 듕

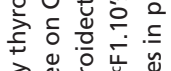

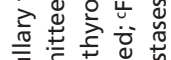
造 है

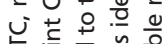

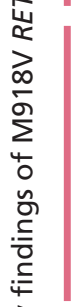

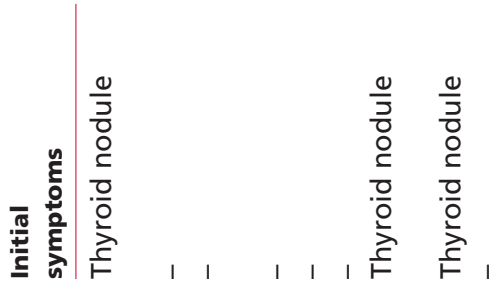

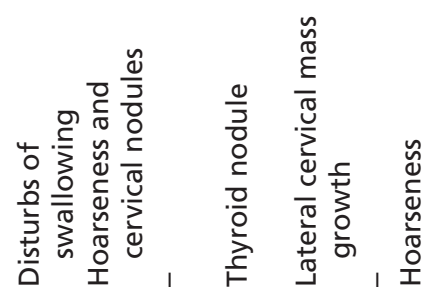

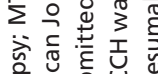
을 흘

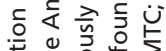

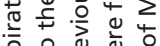
药 类

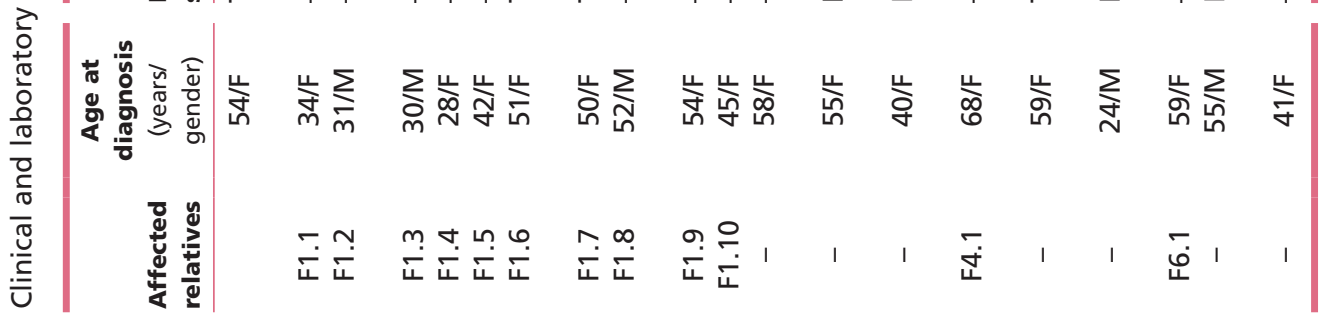
讨

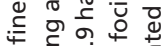

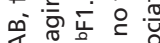

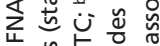
芸 응 ㅎ⿺ㄴ ब

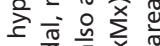

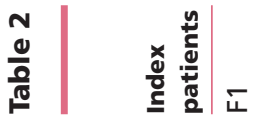
ก $m$ ก

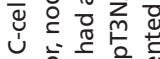

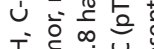


involvement at the time of the initial diagnosis. Two patients (F4 and F6), besides lymph node involvement, also presented persistently very elevated calcitonin levels and distant lesions on imaging methods. The F4 index patient presented a $1-\mathrm{cm}$ highly vascularized hepatic nodule seen by abdominal magnetic resonance imaging (MRI), and the last serum calcitonin on the follow-up is $506 \mathrm{pg} / \mathrm{mL}$. Patient F6 has been diagnosed with cervical and thoracic vertebrae lesions suggestive of metastases 3 years after the thyroidectomy by MRI, and the last serum calcitonin on the follow-up is $1698 \mathrm{pg} / \mathrm{mL}$. No increase in the size of those presumable metastatic lesions of both patients was noted during the follow-up. The remaining index patients presented at their last clinical assessment the following status: one had elevated calcitonin levels $(140 \mathrm{pg} / \mathrm{mL})$ and cervical lateral lymph nodes (F2); one had elevated calcitonin levels $(371 \mathrm{pg} / \mathrm{mL})$ with no structural evidence of disease (F7); 3 had persisted low calcitonin levels $(<10 \mathrm{pg} / \mathrm{mL})$ (F1, F3 and F8) and one had undetectable calcitonin (F5) (Table 2). MTC was present in all surgical specimens and in $7 / 8$ patients presenting multifocal tumor. It is noteworthy that some cases were presumably cured, despite relatively late thyroid surgery (F1, F3, F5 and F8).

To date, 12 relatives carrying the M918V mutation have undergone total thyroidectomy, with confirmation of MTC and/or CCH in the histopathology. As mentioned, 4 of these patients had been already submitted to thyroidectomy when they came up to perform RET screening; 3 of them (patients F1.6, F1.7 and F1.8, Table 2) were already aware of MTC diagnosis after RET screening, and one of them (patient F1.9, Table 2) had been submitted to thyroidectomy because of a thyroid nodule positive

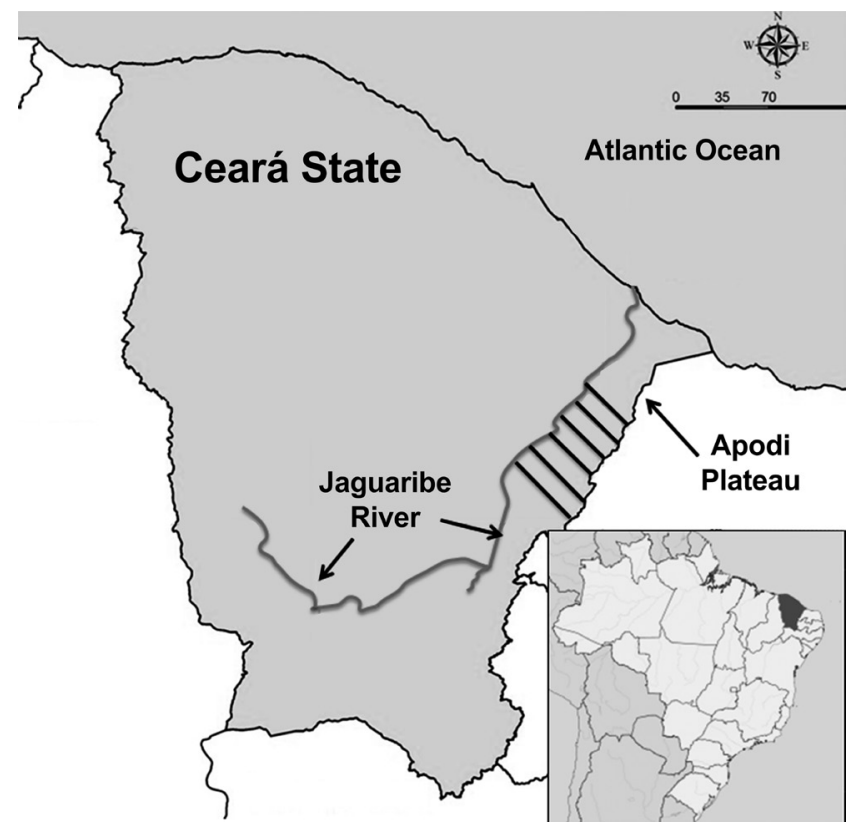

Figure 2

Tracking evidence for RET M918V founder effect. Physical map of South America showing the geographic position of Brazil with the localization of the surrounding physical area of Jaguaribe's valley with its river and Apodi plateau (hatched area) at the Northeastern State of Ceará.

for papillary thyroid carcinoma (PTC). Histopathological review of F1.9 patient confirmed the PTC besides C-cell hyperplasia. In addition, patients F1.8 and F1.10 also demonstrated small PTCs on surgical specimens (Table 2).

In $7 / 12$ relatives carrying the $\mathrm{M} 918 \mathrm{~V}$ mutation with $\mathrm{MTC} / \mathrm{CCH}$, the disease was restricted to the thyroid gland, and the remainder presented metastatic lymph nodes at diagnosis. Seven of 12 relatives achieved undetectable serum calcitonin in the postoperative evaluation.

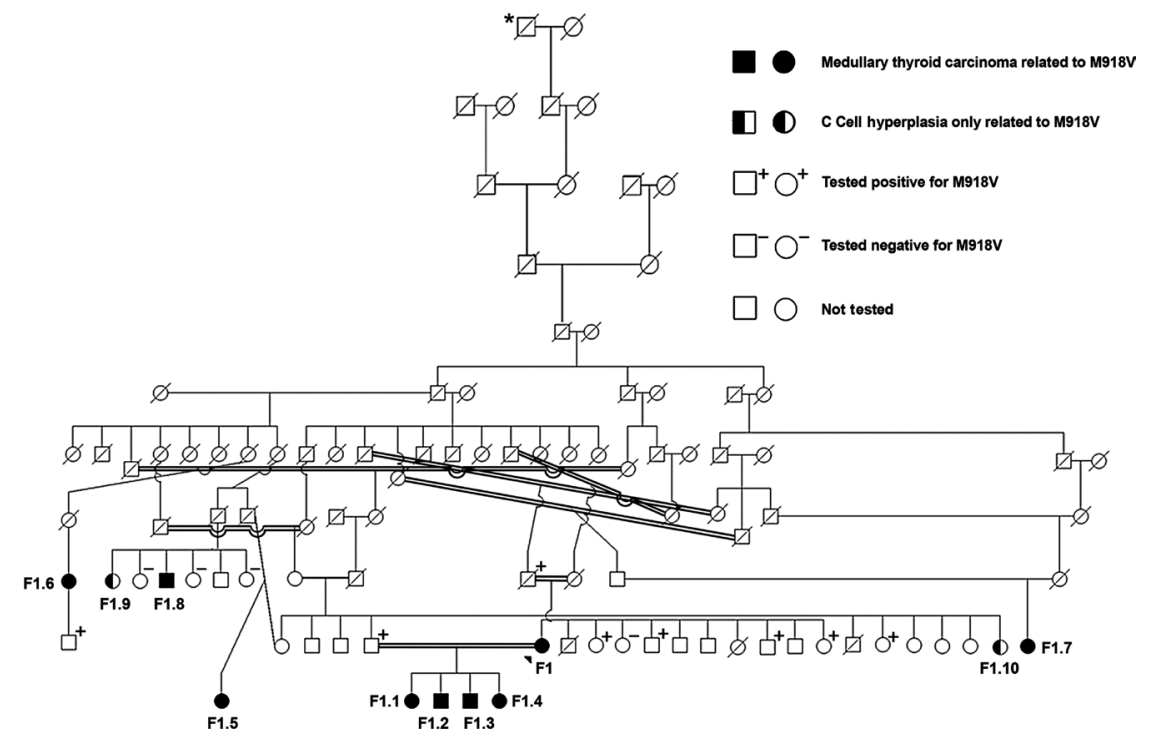

Figure 3

Genotype-phenotype co-segregation in RET M918V largest family. We represent family 1 with the identification of the affected MTC index case by black arrow and relatives. Full black icons represent either the affected MTC proband or relatives, and half-filled icons represent relatives affected by $\mathrm{CCH}$ only. Empty icons with positive (+) signaling represent patients who were tested positive for M918V without clinical evidence of MTC/CCH. Empty icons with negative (-) signaling represent patients who were tested negative for M918V. Empty icons without upper signaling represent individuals who were not submitted to $R E T$ screening. * ${ }^{*}$ epresents the presumed pioneer immigrated to northeastern Brazil from Portugal. 
The clinical and laboratory findings, as well as the surgical extent of all patients with confirmed MTC/CCH are summarized in Table 2.

For the other $30 \mathrm{M} 918 \mathrm{~V}$ carriers, we have decided, after discussions with the medical team and the patients, that a careful follow-up would be a better recommendation than prophylactic surgery because they present normal calcitonin and CEA levels, and no suspicious nodules/lymph nodes on cervical ultrasound. We did not observe statistically significant difference of gender and age between both groups of patients (indicated for surgical treatment, $n=8$ vs clinical follow-up, $n=30$ ). However, the group who performed surgical treatment after RET screening had higher levels of serum calcitonin and a higher frequency of thyroid nodules on the ultrasound (Table 1).

Until the last follow-up visit (up to 5 years of observation), no mutation carrier had presented clinical manifestations or laboratory tests indicating HPTP or PHEO, neither cutaneous lichen amyloidosis nor Hirschsprung's disease. Importantly, clinical assessment of all MTC patients and mutation carriers did not reveal any typical features of MEN 2B, such as musculoskeletal abnormalities; neuromas in the lips, the tongue or the conjunctiva; or ganglioneuromatosis of the intestine.

None of the 40 control individuals presented with the M918V RET mutation.

\section{Tracking the RET M918V founder effect and age of mutation}

Due to the observation that the highest concentration of patients with the M918V RET mutation was in the region that comprises the Jaguaribe River valley and the Apodi plateau (Fig. 2) in the northeast area of the State of Ceará and because the F1 and F6 live in nearby cities $(<25$ miles) of this region, we investigated the presence of a founder effect.

The ethnographic investigation delved into the historical archives of the region with the highest concentration of M918V-affected patients, studying the family ancestor data in the churches and oral life history narratives. After performing a wide pedigree, we observed that some of the M918V MTC patients from this region who were unaware of MTC in other family members belonged to the same family (F1.6, F1.7 and F1.8) (Fig. 3). In 1700s, a pioneer immigrated to northeastern Brazil from Braga, Portugal, colonizing this region in the northeast of Ceará. Both historical registries and oral life history narratives suggested that this colonizer migrated along the Jaguaribe River valley, where he established several settlements.

The haplotype analysis of our founder effect investigation confirmed the qualitative ethnographic data collected. All studied loci were in Hardy-Weinberg equilibrium. Seven patients (33.3\%) from 4 apparently unrelated families shared a common haplotype (D10S197RET-D10S196-D10S1652: 168-M918V-98-170; Fig. 4A). However, only 2 wild-type chromosomes in the control group presented this haplotype $(P<0.001)$. In fact, statistically significant differences in allele frequencies between the wild-type and the M918V RET chromosomes were observed for markers located closer to RET, in particular D10S197, D10S196 and D10S537. This finding
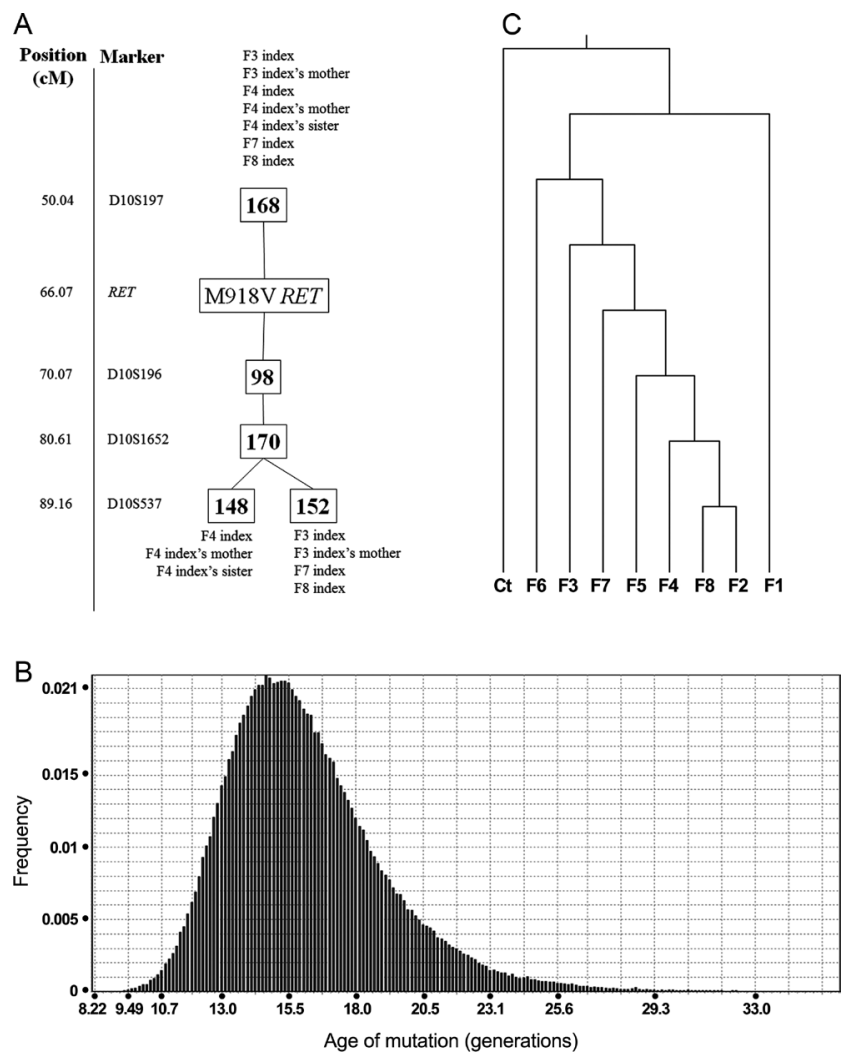

\section{Figure 4}

Tracking founder effect. (A) Haplotype branching trees derived from haplotype analysis of the seven mentioned patients. Family haplotypes are indicated with the corresponding family ID numbers. The markers used are shown together with their position in the deCODE genetic map. Boxed numbers correspond to common allele in respective loci. (B) Histograms of estimated age of M918V RET mutation obtained from DMLE software. The age of mutation is given in number of generations. This histogram was obtained using growth rate of 0.4411 (25 years/generation) and the proportion of sampled chromosome of 0.015 . (C) Phylogenetic tree of all families (numbered from \#1 to \#8) and the control group $(\mathrm{Ct})$.

Published by Bioscientifica Ltd. 
supports our hypothesis that the M918V RET mutation was settled in Ceará state as a founder mutation.

The State of Ceará's population currently includes 8,904,459 people (Instituto Brasileiro de Geografia e Estatística 2015). Historical and demographic data indicate that the population was 721,686 in 1872 (Instituto Brasileiro de Geografia e Estatística 1872). Assuming 25 years/generation, the estimated growth rate was 0.4411 , and assuming 30 years/generation, the estimated growth rate was 0.5294 . Figure $4 \mathrm{~B}$ presents a set of histograms for age estimation. Briefly, we estimated that the founder mutation was settled in Ceará approximately 15 generations ago, which corresponds to 376 years (considering the year/generation 25 years) or 451 years (considering the year/generation 30 years).

The phylogenetic tree (Fig. 4C) revealed that control group shared poor genetic similarity with the patients. Our tree findings revealed that all families coalesce in a common knot, corresponding to a putative most recent common ancestor. Most importantly, our data indicate that different families may be related to each other.

\section{Discussion}

By studying 8 kindreds affected by the RET M918V mutation, we report for the first time that this mutation co-segregates with familial MTC and is inherited with complete penetrance pattern. The RET 918 codon is classically related to the MEN 2B syndrome and has been extensively studied since the first mutation in this codon was reported (Carlson et al. 1994, Hofstra et al. 1994, Eng et al. 1994, Cirafici et al. 1997, Wells et al. 2015). In contrast to the M918T mutation, which causes MEN 2B syndrome with a more aggressive MTC, we did not detect any MEN 2B features in the M918V carriers.

M918V was described for the first time in 2011 in one MTC patient and in one of 3 screened relatives of this patient, who have not developed MTC despite advanced age. In addition, it was characterized as a low transforming mutation by in silico and in vitro analysis (Cosci et al. 2011). Cirafici and coworkers had previously demonstrated that only the mutation M918T exhibited a highly transforming activity from all possible substitutions for methionine 918, including RET M918V, which presented a low transforming potential (Cirafici et al. 1997). More recently, Plaza-Menacho's study revealed that C-terminus oncogenic RET kinase mutants become phosphorylated earlier than the wild-type RET, due to a combination of enhanced kinase activity with ATP affinity, which mechanism is related to a better intermolecular substrate phosphorylation. Moreover, RET M918T leads to cis-inhibitory machinery involving tethering contacts between the glycine-rich loop, activation loop, alpha C-helix and may elicit transactivation in the way of promoting intermolecular autophosphorylation by improving substrate presentation, and therefore, uncontrolled oncogenic activity (Plaza-Menacho et al. 2014). Would RET M918V shed a light on understanding the phenotypic oncogenic spectrum of MEN2B and FMTC? Further scrutinizing studies on M918V mutant mechanism of intermolecular autophosphorylation are still needed.

We evaluated 8 MTC patients referred to us for RET sequencing in whom we detected the M918V mutation and 12 at-risk relatives in whom MTC/CCH was diagnosed after the identification of this mutation. In contrast to the M918T mutation, which causes MEN 2B syndrome with a more aggressive MTC, we did not detect any MEN 2B features in the M918V carriers and a more favorable outcome compared with classical highest-risk M918T mutation carriers. In fact, the clinical presentation was quite heterogeneous, particularly for the age at diagnosis, the TNM staging and the follow-up after thyroidectomy (Table 2). The advanced TNM stage in 2 index cases (F6 and F7, Table 2) was possibly related to the long interval from the manifestation of the initial symptoms to surgical treatment; their follow-up was also remarkable for the highest levels of postoperative serum calcitonin and CEA, suggesting the persistence of disease.

For the relatives whose diagnosis of MTC was performed after the genetic screening, we observed that the mothers (F4.1 and F6.1) of 2 probands had less advanced disease than their children. This finding reinforces the importance of RET mutation screening to diagnose the tumor before the onset of symptoms. Interestingly, we observed that patient $\mathrm{F} 1.8$ was diagnosed at 52 years of age with a tumor (T3mN1aM0) and a micro PTC, whereas his sister (F1.9), who was also submitted to total thyroidectomy due to PTC, presented only CCH. Additionally, an 87-yearold male with a normal calcitonin level and thyroid ultrasound without any nodules recently died from an unrelated condition, whereas his grandson was diagnosed with a multifocal MTC and lateral lymph node metastases at 31 years of age (F1.2) (Table 2). We believe that genetics and environmental factors may contribute to the wide clinical heterogeneity of our patients (Rigotto et al. 2012).

It is well known that, even in large kindreds, the pattern of disease presentation may not become evident until the evaluation of several family members, and even then, it may vary compared with reports of other

Published by Bioscientifica Ltd 
families with the same RET mutation (Wells et al. 2013). Taking into consideration that we have observed only 20 patients with M918V MTC/CCH to date, cervical lymph node metastases were found in $12 / 20$ patients, including 3 patients younger than 35 years (F1.2, F1.4, and F6), and probable distant metastases were noted in $2 / 20$, suggesting a more aggressive behavior of M918V MTC. Patients F4 and F6 presented structural lesions in liver and spinal vertebrae, respectively, which could correspond to distant metastases as they are associated to persistent high levels of calcitonin (above $500 \mathrm{pg} / \mathrm{mL}$ ). However, false-positive results cannot be totally excluded, as these abnormalities were not biopsied.

On the other hand, we observed a relatively favorable presentation among the majority of carriers. Therefore, we believe that assessment and follow-up of a greater number of patients carrying M918V is necessary to get a better understanding about the behavior of MTC related to this novel mutation. In general, a substantial number of patients with distant metastases of MTC may have indolent disease and quiescent or slow-growing lesions over years of routine observation (Cabanillas et al. 2014).

So far, 20 out of $50 \mathrm{M} 918 \mathrm{~V}$ carriers underwent total thyroidectomy and all of them presented MTC/CCH in surgical specimens (Table 2). It is possible that $30 \mathrm{M} 918 \mathrm{~V}$ remaining carriers, who were not submitted to surgical treatment, may present microscopic MTC/CCH whose size did not influence basal calcitonin levels or the formation of a thyroid nodule on US imaging yet. Therefore, we faced an issue that was discussed among the medical team as to how we would deal with M918V carriers who did not present any test suggesting the presence of $\mathrm{MTC} / \mathrm{CCH}$. Presently, there is no recommendation in guidelines about prophylactic thyroidectomy for M918V, so we have decided by a cautious follow-up using basal calcitonin and neck US performed at every 6-month interval.

In fact, when we initially found the first patients with M918V, we were not sure that M918V was a mutation causing disease as up to the present time, the only mutation described in codon 918 was the M918T, classically associated to the MEN 2B phenotype. For those reasons, we opted to perform $R E T$ extended analysis in all M918V who had histopathological confirmation of MTC or CCH. Also, M918V had not been found in 40 thyroidhealthy controls from the same country state.

Moreover, we observed that 2 patients carrying M918V mutation had CCH and PTC (F1.9 and F1.10, Table 2) and 1 patient (F1.8, Table 2) had MTC and PTC. The association of PTC and MTC occasionally occurs, which comes in a variable rate (Biscolla et al. 2004, Machens \& Dralle 2012), depending on the environmental conditions or differences in the study populations (Wells et al. 2015).

We further investigated the ethnographic and quantitative aspects of the dispersion of the M918V RET mutation. All of our data support the hypothesis that a founder effect is responsible for the dispersion of the M918V RET mutation along the Jaguaribe River throughout the State of Ceará, consistent with the higher prevalence of MTC around the northeast of the state. Therefore, our findings substantiate both anecdotal and community health-based evidence collected from the participants during the ethnographic fieldwork. We propose that the Brazilian growth rate followed distinct phases in history and that the constant growth rate portrayed here is a mere mathematical extrapolation. It is also noteworthy that the historical registries of the population in the studied region were not precisely accounted for as we journeyed into the past. However, we encountered consistent information with the aid of the oral life history narratives and the document analysis, which corroborated to our hypothesis that this mutation has accompanied the population of Ceará for approximately 350-400 years and that these 8 supposedly distinct kindreds are one single family that has been dismembered through the years.

Considering the results of biochemical and/or imaging tests used for the investigation of MTC, and the histopathological results for those patients who were submitted to surgical treatment, we observed a low penetrance of this neoplasia among M918V carriers ( $40 \%$ (20/50)). Also, evaluating the median age of the relatives who were M918V carriers according to their status at the $R E T$ screening (already thyroidectomized at RET screening with MTC/CCH confirmation by histopathology: 51.5 years; thyroidectomized after RET screening with MTC/CCH confirmation by histopathology: 36.5 years vs non-thyroidectomized after RET screening: 36.5 years, Table 1), we observed a relatively lower progression of MTC in all subgroups of carriers.

The majority of the MTC patients presented a favorable clinical course, even though there are high frequency of lymph node metastases at initial diagnosis and presumable distant metastasis in 2 patients. In conclusion, based on the heterogeneity of clinical presentation of M918V mutation in our case series, we propose that this mutation should be classified as an ATA moderate-risk mutation and that M918V carriers must undergo total thyroidectomy and neck dissection as appropriate, whenever elevated serum calcitonin or suspicious thyroid nodules or cervical lymph nodes are found. For the M918V carriers without biochemical or imaging tests suggestive of MTC, we believe

Published by Bioscientifica Ltd 
that prophylactic thyroidectomy could be postponed beyond 10 years of age (Wells et al. 2013, 2015).

\section{Declaration of interest}

The authors declare that there is no conflict of interest that could be perceived as prejudicing the impartiality of the research reported.

\section{Funding}

This study was supported by research grants from the Sao Paulo State Research Foundation (FAPESP) to R M B M, J R M M, M R D-S (2006/60402-1) and to R M B M (2010/51547-1 and 2014/06570-6) by FAPESP fellowship grants to S C L (2009/50575-4) and to M S A S (2010/51546-5 and 2012/21942-1) and by a Fleury Group Research Grant (12518). R M B M and A L M are investigators of the Fleury Group.

\section{Author contribution statement}

Drs Dias-da-Silva and Maciel had full access to all the data in the study and take responsibility for the integrity of the data and the accuracy of the data analysis. Drs Martins, Dias-da-Silva and Maciel contributed to study concept and design. Martins-Costa, Cunha, Lindsey, Camacho, Dotto, Furuzawa, Sousa, Kasamatsu, Kunii, Martins, Machado, Martins, Dias-da-Silva and Maciel contributed to the acquisition, analysis or interpretation of data. Martins-Costa, Martins, Dias-da Silva and Maciel drafted the manuscript. Cunha, Sousa, Martins, Dias-da-Silva, and Maciel critically revised the manuscript for important intellectual content. Cunha and Camacho contributed to statistical analysis. Martins, Dias-da-Silva and Maciel obtained funding. Administrative, technical, or material support was given by Furuzawa, Kasamatsu and Kunii. Study was supervised by Martins, Dias-da-Silva and Maciel.

\section{Acknowledgments}

The authors are thankful to the Coordination for the Improvement of Higher Education Personnel, Brazil-Ministry of Education (CAPES) for the support to our Post-Graduation Program. The authors are thankful to the team of the Laboratory of Molecular and Translational Endocrinology. The authors are also thankful to the surgeons in Ceara who performed the surgeries in our patients: André P Cortez, Marcelo E Holanda, Fernando Porto Carreiro-Filho, J Wilson M de Farias, Sérgio B Lima and Luís A Albano Ferreira. Also, the authors acknowledge all patients and relatives who kindly hosted our regional BRASMEN task force in northeast Ceará.

\section{References}

American Joint Committee on Cancer 2010 Thyroid. In AJCC Staging Manual, edn 7th, pp 87-96. Eds SB Edge, DR Byrd \& CC Compton. New York, NY, USA: Springer.

Brandi ML, Gagel RF, Angeli A, Bilezikian JP, Beck-Peccoz P, Bordi C, Conte-Devolx B, Falchetti A, Gheri RG, Libroia A, et al. 2001 Guidelines for diagnosis and therapy of MEN type 1 and type 2 . Journal of Clinical Endocrinology and Metabolism 86 5658-5671. (doi:10.1210/jcem.86.12.8070)

Biscolla RP, Ugolini C, Sculli M, Bottici V, Castagna MG, Romei C, Cosci B, Molinaro E, Faviana P, Basolo F, et al. 2004 Medullary and papillary tumors are frequently associated in the same thyroid gland without evidence of reciprocal influence in their biologic behavior. Thyroid 14 946-952. (doi:10.1089/thy.2004.14.946)

Cabanillas ME, Hu MI \& Jimenez C 2014 Medullary thyroid cancer in the era of tyrosine kinase inhibitors: to treat or not to treat - and with which drug - those are the questions. Journal of Clinical Endocrinology and Metabolism 99 4390-4396. (doi:10.1210/jc.2014-2811)

Caleca L, Putignano AL, Colombo M, Congregati C, Sarkar M, Magliery TJ, Ripamonti CB, Foglia C, Peissel B, Zaffaroni D, et al. 2014 Characterization of an Italian founder mutation in the RING-finger domain of BRCA1. PLOS ONE 9 e86924. (doi:10.1371/ journal.pone.0086924)

Camacho CP, Hoff AO, Lindsey SC, Signorini PS, Valente FO, Oliveira MN, Kunii IS, Biscolla RP, Cerutti JM \& Maciel RM 2008 Early diagnosis of multiple endocrine neoplasia type $2 \mathrm{~B}$ : a challenge for physicians. Archives of Endocrinology and Metabolism $\mathbf{5 2}$ 1393-1398. (doi:10.1590/s0004-27302008000800031)

Camacho CP, Lindsey SC, Kasamatsu TS, Machado AL, Martins JR, Biscolla RP, Dias da Silva MR, Vieira JG \& Maciel RM 2014 Development and application of a novel sensitive immunometric assay for calcitonin in a large cohort of patients with medullary and differentiated thyroid cancer, thyroid nodules, and autoimmune thyroid diseases. European Thyroid Journal 3 117-124. (doi:10.1159/000363055)

Carlson KM, Dou S, Chi D, Scavarda N, Toshima K, Jackson CE, Wells SA Jr, Goodfellow PJ \& Donis-Keller H 1994 Single missense mutation in the tyrosine kinase catalytic domain of the RET protooncogene is associated with multiple endocrine neoplasia type 2B. PNAS 91 1579-1583. (doi:10.1073/pnas.91.4.1579)

Chen H, Sippel RS, O'Dorisio MS, Vinik AI, Lloyd RV \& Pacak K 2010 The North American Neuroendocrine Tumor Society consensus guideline for the diagnosis and management of neuroendocrine tumors: pheochromocytoma, paraganglioma, and medullary thyroid cancer. Pancreas 39 775-783. (doi:10.1097/MPA.0b013e3181ebb4f0)

Cirafici AM, Salvatore G, De Vita G, Carlomagno F, Dathan NA, Visconti R, Melillo RM, Fusco A \& Santoro M 1997 Only the substitution of methionine 918 with a threonine and not with other residues activates RET transforming potential. Endocrinology 138 1450-1455. (doi:10.1210/en.138.4.1450)

Cosci B, Vivaldi A, Romei C, Gemignani F, Landi S, Ciampi R, Tacito A, Molinaro E, Agate L, Bottici V, et al. 2011 In silico and in vitro analysis of rare germline allelic variants of RET oncogene associated with medullary thyroid cancer. Endocrine Related Cancer 18 603-612. (doi:10.1530/ERC-11-0117)

Eng C, Smith DP, Mulligan LM, Nagai MA, Healey CS, Ponder MA, Gardner E, Scheumann GF, Jackson CE, Tunnacliffe A, et al. 1994 Point mutation within the tyrosine kinase domain of the RET proto-oncogene in multiple endocrine neoplasia type $2 \mathrm{~B}$ and related sporadic tumours. Human Molecular Genetics 3 237-241. (doi:10.1093/hmg/3.2.237)

Frank-Raue K \& Raue F 2015 Hereditary medullary thyroid cancer genotype-phenotype correlation. Recent Results in Cancer Research 204 139-156. (doi:10.1007/978-3-319-22542-5 6)

Hofstra RM, Landsvater RM, Ceccherini I, Stulp RP, Stelwagen T, Luo Y, Pasini B, Hoppener JWM, van Amstel HKP, Romeo G, et al. 1994 A mutation in the RET proto-oncogene associated with multiple endocrine neoplasia type $2 \mathrm{~B}$ and sporadic medullary thyroid carcinoma. Nature 367 375-376. (doi:10.1038/367375a0)

Instituto Brasileiro de Geografia e Estatística 1872 Demographic Census. Rio de Janeiro, Brazil: Instituto Brasileiro de Geografia e Estatística. (available at: http://www.ibge.gov.br/)

Instituto Brasileiro de Geografia e Estatística 2015 Estimatives of Brazilian Population on July, 2015. Rio de Janeiro, Brazil: Instituto Brasileiro de Geografia e Estatística. (available at: http://www.ibge.gov.br/)

Kizys MM, Cardoso MG, Lindsey SC, Harada MY, Soares FA, Melo MC, Montoya MZ, Kasamatsu TS, Kunii IS, Giannocco G, et al. 2012 Optimizing nucleic acid extraction from thyroid fine-needle aspiration cells in stained slides, formalin-fixed/paraffin-embedded tissues, and long-term stored blood samples. Archives of Endocrinology and Metabolism 56 618-626. (doi: 10.1590/s000427302012000900004) 
Kloos RT, Eng C, Evans DB, Francis GL, Gagel RF, Gharib H, Moley JF, Pacini F, Ringel MD, Schlumberger M, et al. 2009 Medullary thyroid cancer: management guidelines of the American Thyroid Association. Thyroid 19 565-612. (doi:10.1089/ thy.2008.0403)

Lindsey SC, Kunii IS, Germano-Neto F, Sittoni MY, Camacho CP, Valente FO, Yang JH, Signorini PS, Delcelo R, Cerutti JM, et al. 2012 Extended RET gene analysis in patients with apparently sporadic medullary thyroid cancer: clinical benefits and cost. Hormones and Cancer 3 181-186. (doi:10.1007/s12672-012-0109-7)

Machens A \& Dralle H 2012 Simultaneous medullary and papillary thyroid cancer: a novel entity? Annals of Surgical Oncology 19 37-44. (doi:10.1245/s10434-011-1795-z)

Maeda SS, Borba VZ, Camargo MB, Silva DM, Borges JL, Bandeira F \& Lazaretti-Castro M 2014 Recommendations of the Brazilian Society of Endocrinology and Metabology (SBEM) for the diagnosis and treatment of hypovitaminosis D. Archives of Endocrinology and Metabolism 58 411-433.

Papi L, Putignano AL, Congregati C, Zanna I, Sera F, Morrone D, Falchetti M, Turco MR, Ottini L, Palli D, et al. 2009 Founder mutations account for the majority of BRCA1-attributable hereditary breast/ovarian cancer cases in a population from Tuscany, Central Italy. Breast Cancer Research and Treatment 117 497-504. (doi:10.1007/s10549-008-0190-3)

Plaza-Menacho I, Barnouin K, Goodman K, Martinez-Torres RJ, Borg A, Murray-Rust J, Mouilleron S, Knowles P \& McDonald NQ 2014 Oncogenic RET kinase domain mutations perturb the autophosphorylation trajectory by enhancing substrate presentation in trans. Molecular Cell 53 738-751. (doi:10.1016/j. molcel.2014.01.015)

Qi XP, Ma JM, Du ZF, Ying RB, Fei J, Jin HY, Han JS, Wang JQ, Chen XL, Chen CY, et al. 2011 RET germline mutations identified by exome sequencing in a Chinese multiple endocrine neoplasia type 2A/familial medullary thyroid carcinoma family. PLOS ONE 6 e20353. (doi:10.1371/journal.pone.0020353)

Reeve JP \& Rannala B 2002 DMLE+: Bayesian linkage disequilibrium gene mapping. Bioinformatics 18 894-895. (doi:10.1093/ bioinformatics/18.6.894)
Rigotto RM, Carneiro FF, Marinho AM, Rocha MM, Ferreira MJ, Pessoa VM, Teixeira AC, da Silva MLV, Braga LQV \& Teixeira MM 2012 The green rural economy: challenges to research and to public health policies posed by agricultural modernization. Ciencia e Saude Coletiva 17 1533-1542. (doi:10.1590/S1413-81232012000600017)

Rousset F 2008 genepop'007: a complete re-implementation of the genepop software for Windows and Linux. Molecular Ecology Resources 8 103-106. (doi:10.1111/j.1471-8286.2007.01931.x)

Signorini PS, Franca MI, Camacho CP, Lindsey SC, Valente FO, Kasamatsu TS, Machado AL, Salim CP, Delcelo R, Hoff AO, et al. 2014 A ten-year clinical update of a large RET p.Gly533Cys kindred with medullary thyroid carcinoma emphasizes the need for an individualized assessment of affected relatives. Clinical Endocrinology 80 235-245. (doi:10.1111/cen.12264)

Stephens M \& Donnelly P 2003 A comparison of Bayesian methods for haplotype reconstruction from population genotype data. American Journal of Human Genetics 73 1162-1169. (doi:10.1086/379378)

Stephens M \& Scheet P 2005 Accounting for decay of linkage disequilibrium in haplotype inference and missing-data imputation. American Journal of Human Genetics 76 449-462. (doi:10.1086/428594)

Stephens M, Smith NJ \& Donnelly P 2001 A new statistical method for haplotype reconstruction from population data. American Journal of Human Genetics 68 978-989. (doi:10.1086/319501)

Takezaki N, Nei M \& Tamura K 2010 POPTREE2: software for constructing population trees from allele frequency data and computing other population statistics with Windows interface. Molecular Biology and Evolution 27 747-752. (doi:10.1093/ molbev/msp312)

Wells SA Jr, Pacini F, Robinson BG \& Santoro M 2013 Multiple endocrine neoplasia type 2 and familial medullary thyroid carcinoma: an update. Journal of Clinical Endocrinology and Metabolism 98 3149-3164. (doi:10.1210/jc.2013-1204)

Wells SA Jr, Asa SL, Dralle H, Elisei R, Evans DB, Gagel RF, Lee NY, Machens A, Moley JF, Pacini F, et al. 2015 Revised American thyroid association guidelines for the management of medullary thyroid carcinoma the American thyroid association guidelines task force on medullary thyroid carcinoma. Thyroid 25 567-610. (doi:10.1089/ thy.2014.0335)

Received in final form 5 October 2016 Accepted 7 October 2016 (c) 2016 Society for Endocrinology Printed in Great Britain
Published by Bioscientifica Ltd 